\title{
High frequency of known copy number abnormalities and maternal duplication 15q11- q13 in patients with combined schizophrenia and epilepsy
}

\author{
Larissa R Stewart ${ }^{\dagger}$, April L Hall ${ }^{\dagger}$, Sung-Hae L Kang, Chad A Shaw and Arthur L Beaudet ${ }^{*}$
}

\begin{abstract}
Background: Many copy number variants (CNVs) are documented to be associated with neuropsychiatric disorders, including intellectual disability, autism, epilepsy, schizophrenia, and bipolar disorder. Chromosomal deletions of 1q21.1, 3q29, 15q13.3, 22q11.2, and NRXN1 and duplications of 15q11-q13 (maternal), 16p11, and 16 p13.3 have the strongest association with schizophrenia. We hypothesized that cases with both schizophrenia and epilepsy would have a higher frequency of disease-associated CNVs and would represent an enriched sample for detection of other mutations associated with schizophrenia.

Methods: We used array comparative genomic hybridization (CGH) to analyze 235 individuals with both schizophrenia and epilepsy, 80 with bipolar disorder and epilepsy, and 191 controls.

Results: We detected 10 schizophrenia plus epilepsy cases in 235 (4.3\%) with the above mentioned CNVs compared to 0 in 191 controls $(p=0.003$ ). Other likely pathological findings in schizophrenia plus epilepsy cases included 1 deletion $16 \mathrm{p} 13$ and 1 duplication $7 q 11.23$ for a total of 12/235 (5.1\%) while a possibly pathogenic duplication of 22q11.2 was found in one control for a total of 1 in $191(0.5 \%)$ controls $(p=0.008)$. The rate of abnormality in the schizophrenia plus epilepsy of 10/235 for the more definite CNVs compares to a rate of 75/7336 for these same CNVs in a series of unselected schizophrenia cases $(p=0.0004)$.

Conclusion: We found a statistically significant increase in the frequency of CNVs known or likely to be associated with schizophrenia in individuals with both schizophrenia and epilepsy compared to controls. We found an overall $5.1 \%$ detection rate of likely pathological findings which is the highest frequency of such findings in a series of schizophrenia patients to date. This evidence suggests that the frequency of disease-associated CNVs in patients with both schizophrenia and epilepsy is significantly higher than for unselected schizophrenia.
\end{abstract}

\section{Background}

The genetic contribution to the etiology of schizophrenia is significant, but the full molecular basis of the genetic factors remains incompletely defined. Since at least 1992 [1], it has been known that deletion of chromosome 22q11.2 is associated with schizophrenia with a very substantial relative risk. One study of 78 adults with deletion $22 \mathrm{q} 11.2$ found that $22.6 \%$ had

\footnotetext{
* Correspondence: abeaudet@bcm.edu

† Contributed equally

Department of Molecular and Human Genetics, Baylor College of Medicine, Houston, TX 77030 USA
}

schizophrenia [2]. Recurrent seizures were found in $39.7 \%$, which may be explained in part by the hypocalcemia associated with this phenotype. In 2008, two studies $[3,4]$ found that chromosomal deletions of 1q21.1, $15 \mathrm{q} 13.3$, and $22 \mathrm{q} 11.2$ were associated with markedly increased risk of schizophrenia; one report but not the other also suggested a role for deletion 15q11.2. These three most frequent deletions were found in $0.21 \%$, $0.20 \%$, and $0.26 \%$ respectively of the schizophrenic populations studied, and they are also associated with intellectual disability and autism [5,6]. It is quite remarkable that each of these CNVs can be associated 
with a wide range of phenotypes including intellectual disability, autism, schizophrenia, and epilepsy [7]. Deletion $15 \mathrm{q} 13.3$ is also reported to be present in as many as $1 \%$ of individuals with idiopathic generalized epilepsy [8]. For the 15q13.3 deletion, the CHRNA7 gene encoding the $\alpha 7$ subunit of the neuronal nicotinic receptor is a strong candidate gene mediating the phenotypic effects, as further supported by smaller deletions causing similar phenotypes [9]. The other two deletions (1q21.1 and $22 \mathrm{q} 11.2$ ) encompass many genes with no one gene yet strongly implicated as mediating the phenotypic effects. Other chromosomal mutations have also been found in schizophrenia such as deletions of 3q29 and NRXN1 and duplications of 15q11-q13 (maternal), 16p11.2, and 16p13.3 [10-14]. Deletions of chromosome $16 \mathrm{p} 11.2$ are particularly common in autism $[15,16]$, and there is evidence that reciprocal duplications are associated with schizophrenia [11]. There is also evidence that loss-of-function mutations in individual genes can be associated with autism and/or schizophrenia. These genes include or may include DISC1, NRXN1, PDE4B, NPAS3, CNTNAP2, and APBA2; see Sebat et al. [7] for bibliography.

We reasoned that the frequency of detectable CNVs associated with schizophrenia might be higher in subjects with both schizophrenia and epilepsy compared to either phenotype alone. There is a report that patients with schizophrenia have an 11-fold increase in the prevalence of comorbid epilepsy [17]. We analyzed DNA from subjects with both schizophrenia and idiopathic epilepsy or with bipolar disorder and idiopathic epilepsy and from controls using array comparative genomic hybridization $(\mathrm{CGH})$.

\section{Methods}

\section{Subjects}

DNA samples from 235 subjects with both schizophrenia and idiopathic epilepsy, 80 subjects with both bipolar disorder and idiopathic epilepsy, and 191 controls derived from cultured lymphoblasts, were obtained from the National Institute of Mental Health Human Genetics Initiative (NIMH-HGI). The NIMH website for this collection https://www.nimhgenetics.org/nimh_human_genetics_initiative/ reports that the establishment of a diagnosis of schizophrenia or bipolar disorder was based on DSM-III-R and DSM-IV criteria following a systematic and comprehensive examination of multiple sources of available information obtained from relatives, medical records, and direct assessment using the Diagnostic Interview for Genetic Studies for each patient. A selfreported questionnaire completed by the subjects was used to identify individuals who also had epilepsy in addition to a diagnosis of schizophrenia or bipolar disorder. Subjects reporting seizures secondary to causes such as trauma, medication, and/or polydypsia were excluded. Some patients with self-reported seizures but no further detail about etiology of their seizures were included. Ethnicity for the schizophrenia plus epilepsy samples was 135 Caucasian, 62 black, 22 Asian, 8 Hispanic, and 6 other. Ethnicity for the bipolar plus epilepsy was 77 Caucasian, 1 other, and 2 unknown. Ethnicity for the controls was $100 \%$ Caucasian. We screened Caucasian control individuals for psychiatric symptoms based on their self reported questionnaire. We chose to exclude controls with even modest or questionable behavioral findings in an attempt to exclude individuals who might have mild manifestations of a deleterious CNV. The rationale was to obtain a control group with under-representation of any behavioral abnormalities. Control individuals were excluded if they saw a doctor and took medication or used drugs and alcohol to deal with their depression or anxiety, if they reported any behaviors suggestive of obsessive compulsive disorder, or if they had a history of substance and/or alcohol abuse/dependence. We excluded 1284 samples out of 1920 leaving 636 control samples for study. Then 191 of the 636 were selected at random for study. This high exclusion rate was surprising, but it was already known that lifetime prevalences for depressive, anxiety, and substance use diagnoses were higher than in some other sample collections [18]. Additional information regarding screening criteria can be found in Additional file 1. Another study using these controls excluded far fewer samples based on rescreening [19].

\section{Array CGH}

Blood collected from schizophrenia, bipolar disorder, and control samples was used to establish lymphoblastoid cell lines and DNA was extracted by Rutgers University Cell and DNA Repository, Piscataway, NJ. Blood DNA was not available for most samples, so it was not possible to test whether results were only in lymphoblast DNA and absent in blood DNA. All cases and controls were hybridized with the same Caucasian male reference DNA isolated from fresh blood. Although it is well known that using DNA from lymphoblast cell-lines can give rise to artifactual copy number changes $[20,21]$, these usually do not produce CNVs identical to those known to cause neurobehavioral phenotypes and more often involve aneuploidy, very large genomic changes, or deletions at immunoglobulin genes.

Array CGH was performed on cases and controls with once-used, stripped clinical v8.0 arrays from the Medical Genetics Laboratory (MGL) at Baylor College of Medicine (BCM). Specifically, the v8.0 array is a $180 \mathrm{~K}$ Agilent oligonucleotide array with $30 \mathrm{~kb}$ backbone coverage and exon by exon coverage for 1714 genes reported to be associated with or cause disease or considered to be 
candidates for neurological disease association [22] http://www.bcm.edu/geneticlabs/test_detail.cfm?testcode $=8655$. The array was designed by Pawel Stankiewicz, March 2006 and manufactured by Agilent Technology (Santa Clara, CA). Previously used slides from both abnormal and normal cases were stripped by boiling in a $5 \mathrm{mM}$ potassium phosphate buffer solution for 2 minutes. The reuse of clinical arrays provided a major cost reduction for these studies and allowed for comparison to a large body of clinical data using the same array design. We have experience that the used arrays detect known variants reliably if the Agilent DLR score is less than 0.30 . These data indicate that false negative results would be rare. There is no significant concern regarding false positive results, because all CNVs were validated using new arrays with coverage suitable for the putative CNV.

The procedures for DNA digestion, labeling, and hybridization for the oligonucleotide arrays were performed according to the manufacturers' instructions, with minor modifications [23]. Slides were scanned into image files using the Agilent G2565 Microarray Scanner. Scanned images were quantified using Agilent Feature Extraction software (v10.7.3.), then analyzed for copynumber change using our in-house analysis package, as described previously [24-26]. All calls made with the inhouse software were visually inspected to assess their validity. Additional information on analysis can be found in Additional file 1.

Common CNVs, CNVs located in introns or in nongenic regions, and calls less than one kb were noted in the analysis but are not reported here. Common calls, as defined by being seen more than 20 times in 20,000 cases analyzed by the Medical Genetics Laboratories at Baylor College of Medicine, were also not included. Array data has been deposited in the GEO database under accession number GSE23703. All coordinates are based on the Feb. 2009 UCSC Human Genome Browser assembly (hg19).

All calls reported were validated on a variety of fresh, higher resolution arrays, depending on the coverage of the region in question and included: a custom Agilent 1 $\mathrm{M}$ array designed to cover the great majority of exons in the genome (Celestion-Soper submitted manuscript), Agilent SurePrint G3 Human CGH $4 \times 180$ catalog array (design ID: 022060), and a gene targeted custom arrays (all Agilent Technologies, Santa Clara, California, USA). All arrays used in this study were designed and analyzed based on UCSC hg18 (NCBI Build 36), March 2006. For CNVs that did not have adequate coverage on the $4 \times 180$ Agilent catalog, custom Agilent $4 \times 180 \mathrm{k}$ or $8 \times 60 \mathrm{k}$ arrays with focused coverage for the regions of interest were designed using Agilent's E-array database. The array designs can be viewed on Agilent's e- array database https://earray.chem.agilent.com/earray/ (SSC Tiling v2.0: 027305, SSC Focused v3.0: 028249, Focused v4.0: 028812).

CNVs found in our study were compared to those in the DGV database http://projects.tcag.ca/variation/. Entries in the DGV database that were smaller than or overlapped for less than $10 \%$ of our calls were not counted. IDENTICAL indicates one or more CNVs were found in the database to be identical to our $\mathrm{CNV}$ +or- $10 \%$ on either side. The publication by Levinson et al. [19] analyzed most of the same NIMH samples reported here. A tabulation of all CNV findings in individual samples reported here is available from the corresponding author.

\section{Results and Discussion}

DNA from 235 subjects with both schizophrenia and idiopathic epilepsy, 80 subjects with bipolar disorder and idiopathic epilepsy, and 191 controls was analyzed using array CGH. Out of 235 subjects with both schizophrenia and idiopathic epilepsy, we identified $10 \mathrm{CNVs}$ well established to be associated with schizophrenia (see references in Background above), These included three deletions of $1 \mathrm{q} 21.1$, one deletion of 2p16.3 (NRXN1), one deletion of $15 \mathrm{q} 13.3$, two maternal duplications of $15 \mathrm{q} 11-\mathrm{q} 13$, and three deletions of $22 \mathrm{q} 11.2$ (Figure 1 and Table 1). We also found two other CNVs that have a well established role in other neuropsychiatric phenotypes or epilepsy. These included a deletion of 16p13.1 which is associated with intellectual disability and more recently with schizophrenia [27] and a duplication of the Williams-Bueren syndrome region (7q11.23) which is well documented to be associated with neuropsychiatric phenotypes [28]. In total we found 12 out of 235 cases of schizophrenia and epilepsy (5.1\%) harbored CNVs highly likely to have a significant association with the disease phenotype. This is the highest detection rate for pathological CNVs in any schizophrenia population studied to date.

Among cases with schizophrenia plus epilepsy, we identified many deletions of uncertain significance but with some published link to neuropsychiatric disease. Single cases of deletions were observed for $20 \mathrm{p} 13$, CHRNB3, DLG2, GRIP1, and SLC1A1 (Figure 2 and Table 2). A genome wide linkage analysis for autosomal dominant schizophrenia within a single Israeli Arab pedigree demonstrated a significant linkage association with 20p13 [29] and a linkage analysis of 270 Irish high-density families with varying psychotic illnesses showed a potential linkage of the behavioral phenotypes to a region on 20p that includes 20p13 [30]. There are multiple candidate genes in the linkage interval. CHRNB3, a nicotinic receptor, is reported to be associated with smoking behavior by GWAS [31] and to show linkage 

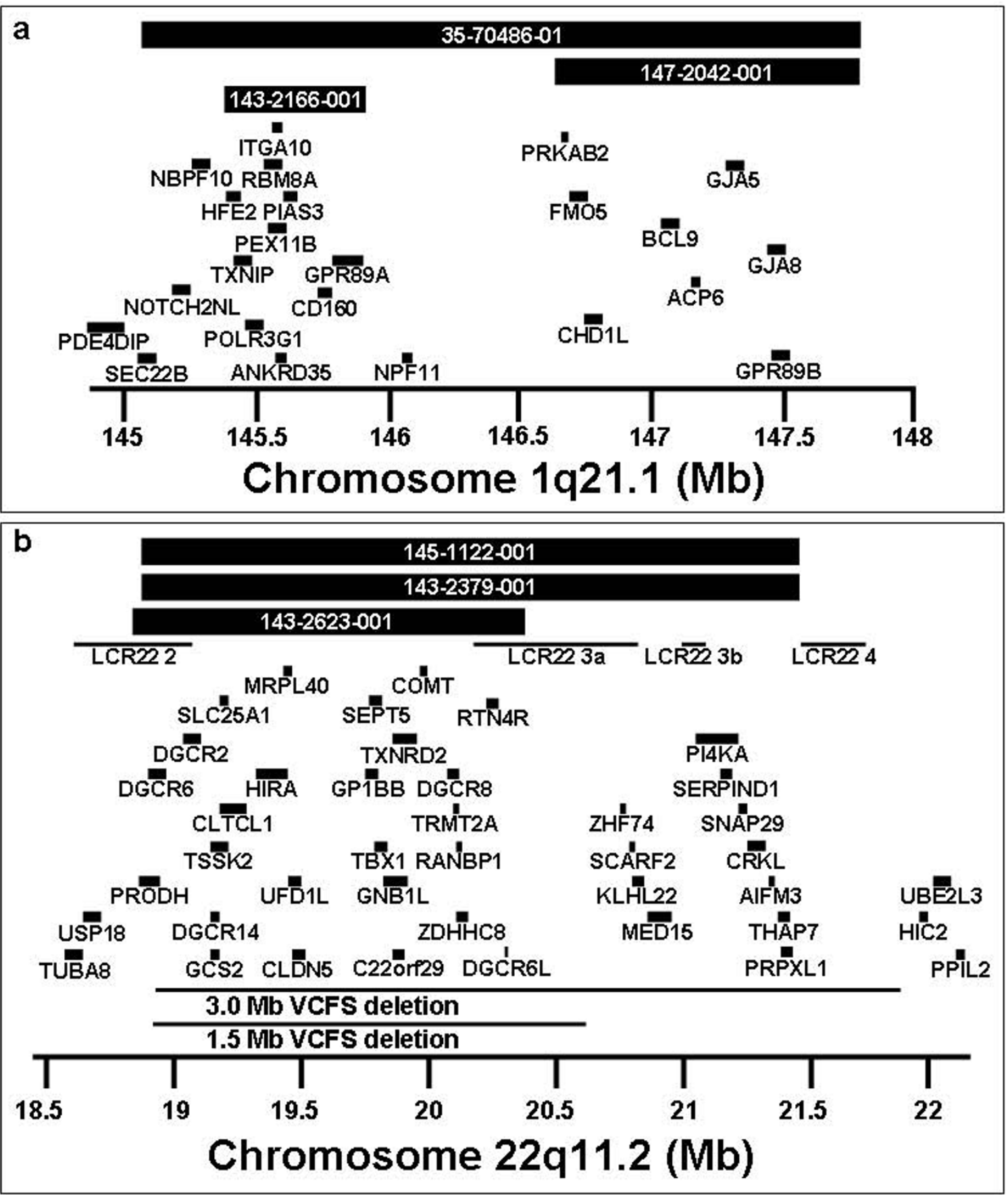

Figure 1 Most frequent pathogenic microdeletions observed in NIMH cases with both schizophrenia and epilepsy. Three cases of deletion 22q11.2 and three cases of deletion 1q21.1 are shown. Unique identifiers from the NIMH collection are provided. Low copy repeat (LCR) regions and gene symbols are provided. Coordinates are based on hg19.

to epilepsy in one study [32]. DLG2 encodes a family member of the membrane-associated guanylate kinase (MAGUK) proteins which are part of the postsynaptic density and interact with receptors, ion channels, and other signaling proteins. Other members of the postsynaptic density such as PSD95 and SAP97 are reported to have altered expression in schizophrenia and epilepsy [33-35]. GRIP1 is a member of the glutamate receptor interacting proteins and has been reported to show altered expression in schizophrenia brain $[36,37]$. 
Table 1 CNV abnormalities of likely significance in cases with both schizophrenia and epilepsy.

\begin{tabular}{|c|c|c|c|c|c|c|c|c|}
\hline NIMH ID & Sex & Chr. & Start & Size (bp) & $C N V$ & Genes & Validation & $D G V$ \\
\hline $35-70486-01$ & M & $1 \mathrm{q} 21.1$ & 145009580 & 2814627 & Loss & 36 & Cat & Identical \\
\hline $147-2042-001$ & M & $1 \mathrm{q} 21.1$ & 146506369 & 1317838 & Loss & 15 & Cat & Identical \\
\hline $143-2166-001$ & M & $1 \mathrm{q} 21.1$ & 145388414 & 444581 & Loss & 17 & Cat & Identical \\
\hline $147-2403-001$ & $\mathrm{~F}$ & $2 p 16.3$ & 50579352 & 428671 & Loss & NRXN1 & Cat & Identical \\
\hline 143-2074-001 & M & $7 q 11.23$ & 72876647 & 563297 & Gain & 15 & Cus4 & Identical \\
\hline 32-11055 & $\mathrm{F}$ & $15 q 11-q 13$ & 21213950 & 4994696 & Gain & 30 genes, SNORDs & Cat & Identical \\
\hline 144-1023-001 & M & $15 q 11-q 13$ & 22842145 & 6189545 & Gain & 28 genes, SNORDs & Cat & Identical \\
\hline $142-1340-001$ & M & $15 q 13.3$ & 30587903 & 2320279 & Loss & 16 & MLPA & Identical \\
\hline $145-1243-001$ & M & $16 p 13.11$ & 15131782 & 1117825 & Loss & 10 & Cat & Identical \\
\hline $145-1122-001$ & M & $22 q 11.21$ & 18894894 & 2569166 & Loss & 58 & Cat & Identical \\
\hline $143-2379-001$ & M & $22 q 11.21$ & 18894894 & 2569166 & Loss & 58 & Cat & Identical \\
\hline $143-2623-001$ & M & $22 q 11.21$ & 18890615 & 1469118 & Loss & 36 & SNP & Identical \\
\hline
\end{tabular}

Abbreviations: M, male; F, female; Chr, chromosome; bp, base pair; CNV, copy number variant; DGV, Database of genomic variants. For validation: Cat $=4 \times 180$ Agilent catalog array; Cus1, Cus2, etc. refer to custom designed focused arrays 1, 2, etc.; MLPA-multiplex ligation-dependent probe amplification, SNP-Illumina 610 quad SNP catalog array.

A study of genotyped autistic patients and matched controls showed an association of a SNP within a genomic region of GRIP1 with autism [38]. Linkage to the region containing, $S L C 1 A 1$, a glutamate transporter, has been reported for obsessive compulsive disorder [39,40], and a SNP near SLC1A1 was reported to show association with autism spectrum disorder [41].

Similarly, duplications of uncertain significance but with some published link to neuropsychiatric disease were found in five schizophrenia plus epilepsy cases. These included duplications of $6 \mathrm{q} 15,16 \mathrm{p} 13.2,19 \mathrm{p} 13.3$, CHRNA7, and SLC6A4 (Table 3). The 6q15 duplication contains HTR1E which encodes a serotonin receptor and has been suggested to be of interest in suicide [42], and attention-deficit/hyperactivity disorder [43]. The16p13.2 region contains ABAT which encodes a $\gamma$ aminobutyrate transaminase that is responsible for the conversion of GABA to succinic semialdehyde (OMIM 137150). This locus has been reported to show altered expression in epilepsy [44] and genetic association in autism [45]. There is some evidence for linkage to autism at $19 \mathrm{p} 13.3$ in a Finnish pedigree [46]. CHRNA7 small duplications are common in the population and may have some pathogenic significance [47], and at least

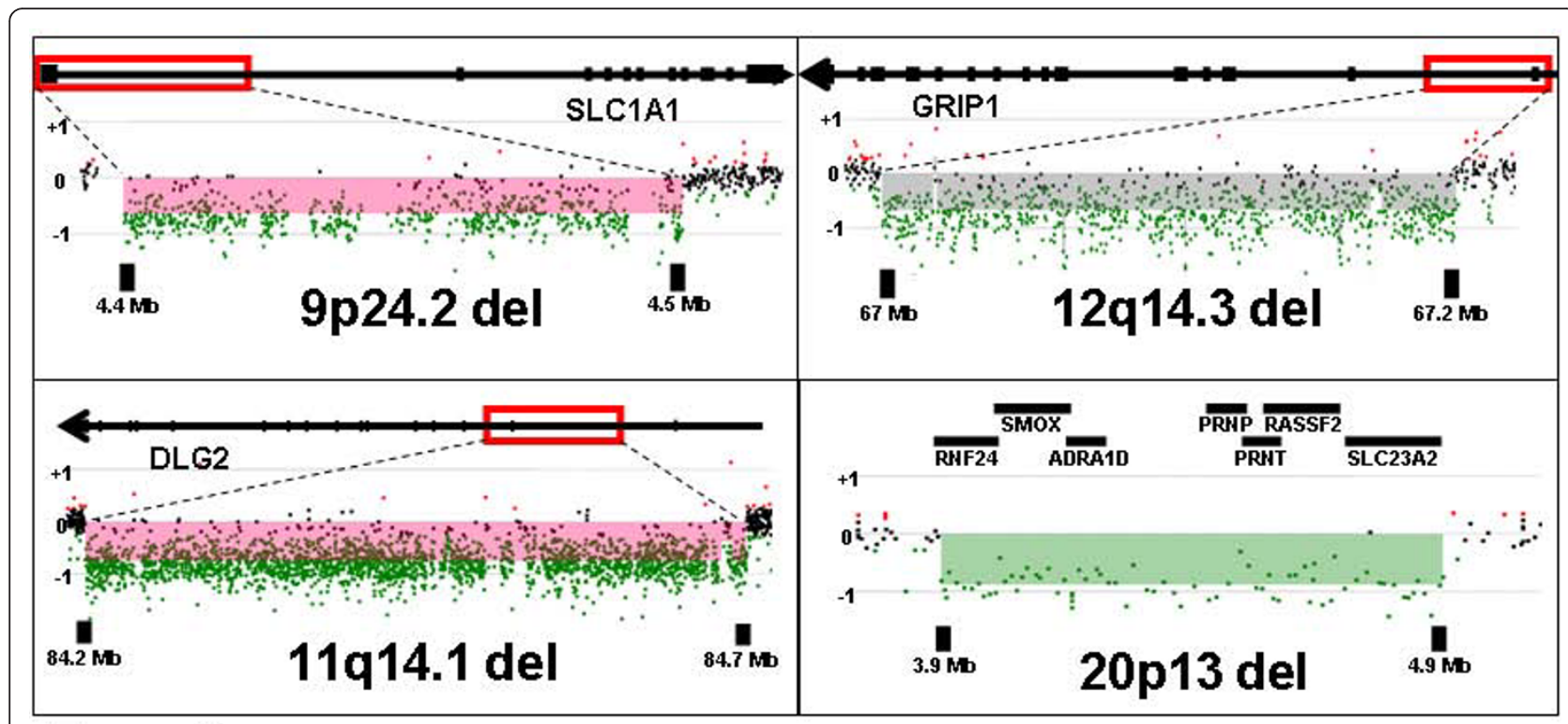

Figure 2 Microdeletions of uncertain significance with some published link to neuropsychiatric disease observed in NIMH cases with both schizophrenia and epilepsy. Deletions on specific Agilent custom arrays for validation are shown involving an exon of DLG2, an exon of SLC1A1, an exon of GRIP1, and multiple genes at the 20 p13 locus as labeled. The regions of deletion are demarcated by red rectangles. Each dot represents an oligonucleotide, green for deleted and black for normal copy number. 
Table 2 CNVs abnormalities of possible significance in cases with both schizophrenia and epilepsy.

\begin{tabular}{ccccccccc}
\hline NIMH ID & Sex & Chr. & Start & Size $(b p)$ & CNV & Genes & Validation & DGV \\
\hline $140-2082-001$ & M & $8 p 11.21$ & 42582092 & 7817 & Loss & CHRNB3 & Cus2 & None \\
$143-2447-001$ & M & $9 p 24.2$ & 4409405 & 134869 & Loss & SLC1A1 & Cus2 & 2 overlap \\
$144-1472-001$ & M & $11 q 14.1$ & 84188228 & 482969 & Loss & DLG2 & Cus2 & None \\
$147-2093-001$ & M & $12 q 14.3$ & 67049795 & 150443 & Loss & GRIP1 & Cus4 & None \\
$144-1461-001$ & M & $20 p 13$ & 3897943 & 1039259 & Loss & 12 & Cat & None \\
\hline
\end{tabular}

Abbreviations: As in Table 1.

one was reported in schizophrenia [3]. We identified two CHRNA7 duplications in schizophrenia patients and one in a bipolar disorder patient; however, we also found one in our controls. This duplication is quite common, but its phenotypic significance is not clear
[47]. SLC6A4 encodes a protein involved in the transport of serotonin and there is a report of genetic association with schizophrenia [48]. Additional findings of unknown significance in schizophrenia plus epilepsy samples are listed in Table 3.

Table 3 CNVs of unknown significance in schizophrenia and epilepsy samples

\begin{tabular}{|c|c|c|c|c|c|c|c|c|}
\hline NIMH ID & Sex & Chr. & Start & Size (bp) & & Genes & Validation & $D G V$ \\
\hline 142-1320-001 & M & $2 p 21$ & 44531130 & 68210 & Loss & SLC3A1, PREPL, C3orf34 & Cus1 & 2 overlap \\
\hline 149-1129-001 & $\mathrm{F}$ & $2 \mathrm{p} 16.1$ & 56091146 & 13954 & Gain & EFEMP1 & Cus4 & None \\
\hline $49-1020-001^{a}$ & $\mathrm{~F}$ & $4 q 28.2$ & 129774971 & 154534 & Gain & PHF17, SCLT1 & Cus4 & Identical \\
\hline 53-10259 & $\mathrm{F}$ & $6 \mathrm{p} 22.3$ & 17465076 & 387198 & Gain & 4 & Cus4 & 1 overlap \\
\hline 70-11763 & $\mathrm{F}$ & $6 \mathrm{p} 22.3$ & 22272906 & 148050 & Loss & $P R L$ & Cus4 & 1 overlap \\
\hline 144-1291-001 & M & $6 q 14.1$ & 76607923 & 25447 & Loss & MYO6, IMPG1 & Cus1 & None \\
\hline 54-10078 & $\mathrm{F}$ & $6 q 15$ & 87456408 & 730692 & Gain & 9 & Cus4 & 3 overlap \\
\hline 144-1096-001 & M & $7 q 11.22$ & 71029067 & 240023 & Gain & WBSCR17, CALN1 & Cat & Identical \\
\hline 142-1006-001 & $\mathrm{F}$ & 7q31.32 & 122364506 & 676522 & Gain & CADPS2, TAS2R16, SLC13A1 & Cus4 & 5 overlap \\
\hline 149-1114-001 & M & $8 q 21$ & 84569675 & 844484 & Loss & $R A L Y L$ & Cat & 1 overlap \\
\hline $54-10151^{a}$ & M & $9 p 24.3$ & 115980 & 471438 & Loss & 5 & Cat & Common \\
\hline 141-0680-001 & $\mathrm{F}$ & 9p24.1 & 6451073 & 394797 & Gain & UHRF2, GLDC, KDMAC & Cus4 & 4 overlap \\
\hline 142-1340-001 & M & $12 \mathrm{p} 13.33$ & 1949926 & 37541 & Loss & CACNA2D4 & Cus1 & 1 overlap \\
\hline 143-2467-001 & M & $12 \mathrm{p} 13.33$ & 1949882 & 34631 & Loss & CACNA2D4 & Cus1 & 1 overlap \\
\hline 146-2019-001 & M & $12 \mathrm{p} 11.22$ & 29009447 & 562052 & Gain & FAR2, ERGIC2 & Cat & 1 overlap \\
\hline $142-1274-001$ & M & $13 q 34$ & 110957062 & 275718 & Gain & $C O L 4 A 2, R A B 20$ & Cus4 & 1 overlap \\
\hline 140-2154-001 & M & $13 q 34$ & 114476840 & 148441 & Gain & FLJ44054, GAS6, FAM70B & Cus4 & 2 overlap \\
\hline 144-1307-001 & M & $15 q 11.2$ & 22842143 & 244550 & Gain & TUBGCP5, CYFIP1, NIPA2,NIPA1 b & MLPA & Common \\
\hline $147-2423-001$ & M & $15 q 13.3$ & 32296138 & 142658 & Gain & CHRNA7 ${ }^{\mathrm{b}}$ & MLPA & Common \\
\hline $35-71412-02$ & M & $15 q 13.3$ & 32296138 & 164344 & Gain & CHRNA7 $^{\mathrm{b}}$ & MLPA & Common \\
\hline $42-1051-002$ & $\mathrm{~F}$ & $16 p 13.2$ & 8969708 & 103443 & Gain & USP7 & Cat & 1 overlap \\
\hline 143-2384-001 & M & 16p13.2 & 8581817 & 830333 & Gain & 9 & Cat & 1 overlap \\
\hline 147-2080-001 & M & $16 \mathrm{p} 13.12$ & 12771677 & 165576 & Loss & CPPED1 & Cat & 2 overlap \\
\hline $54-10151^{a}$ & M & $17 p 13.3$ & 2995336 & 422668 & Gain & 14 & Cat & 1 overlap \\
\hline $54-10151^{a}$ & M & $17 p 13.2$ & 3743015 & 483613 & Gain & $8^{\mathrm{b}}$ & Cat & 2 overlap \\
\hline $49-1020-001^{a}$ & F & $17 p 12$ & 14111831 & 1330176 & Gain & 9 & Cat & Identical \\
\hline $142-1278-001$ & M & 17p12 & 14897946 & 148020 & Loss & CDRT7 & Cus4 & Identical \\
\hline 144-1594-001 & M & 17p11.2 & 21311601 & 50888 & Gain & $\operatorname{KCN} J 12^{b}$ & Cus3 & Identical \\
\hline 148-2171-001 & M & $17 q 11.2$ & 28524944 & 21111 & Gain & SLC6A4 & Cus1 & None \\
\hline $35-08447-02$ & M & $18 q 11-q 12$ & 24744073 & 458607 & Gain & CHST9 & Cus4 & None \\
\hline 30-11632 & $\mathrm{F}$ & 19p13.3 & 6427852 & 429890 & Gain & 14 & Cus4 & None \\
\hline $143-2526-001$ & M & $19 q 13.42$ & 54646013 & 1707820 & Gain & 87 & Cat & 7 overlap \\
\hline
\end{tabular}

Abbreviations: As in Table 1.

a denotes samples having more than one CNV.

b denotes cases which had a similar call to CNV found in controls. 
For the 80 subjects with both bipolar disorder and epilepsy, only 13 CNVs were identified but the number of cases studied was relatively small. Bipolar disorder was previously reported to have a lower CNV detection rate as compared to schizophrenia [49]. The findings in patients with both bipolar disorder and epilepsy are listed and discussed in Additional file 1 Table S1.

The findings in the cases were compared to findings in the NIMH controls screened to reduce the frequency of psychiatric symptoms as discussed above. One control was found to have a duplication of 22q11.2. Duplications of 22q11.2 show incomplete penetrance and cause a highly variable phenotype of neurocognitive dysfunction [50,51], although there is at least one report suggesting an association with schizophrenia [10]. Although we screened out a large fraction of controls based on psychiatric symptoms, this individual passed that screen. Yet this male control with duplication $22 \mathrm{q} 11.2$ is noteworthy for self-reporting two episodes of depression lasting for four weeks accompanied by use of drugs or alcohol more than once for these problems. He also reported that drinking of alcohol interfered with school, job or home life once or twice in the past. He reported the use amphetamines, marijuana, and cocaine, and that this use interfered with school, job or home life 3-5 times. (We excluded controls reporting such drug use 6 or more times.) We also found a $15 \mathrm{q} 11.2$ deletion in one control sample, and though this $\mathrm{CNV}$ is reported to be associated with schizophrenia by some authors [3], the penetrance is quite low [12].

Other findings in controls involving loci of some neurobehavioral relevance included deletions of CNTN4 and GABRR1 and duplications of 15q11.2. Table 4 for complete list of CNVs found in controls.

We wished to assess whether the frequency of disease-related CNVs was significantly more frequent in patients with schizophrenia and epilepsy compared to controls from the same repository and tested on the same array platform. For this assessment, we accepted the following CNVs as being known to be associated with schizophrenia based on published data [12,19]: deletions of 1q21.1, 3q29, 15q13.3, 22q11.2, and NRXN1 and duplications of 15q11-q13 (maternal), $16 \mathrm{p} 11$, and $16 \mathrm{p} 13.3$. We included maternal duplications of $15 \mathrm{q} 11-\mathrm{q} 13$ in this group because of the extensive literature linking it to autism and to epilepsy and based on recent reports of its occurrence in schizophrenia [14,52]. We detected 10 schizophrenia plus epilepsy cases in 235 (4.3\%) with the above mentioned CNVs compared to 0 in 191 controls (Fisher's exact test, $\mathrm{p}=0.003)$. Other likely pathological findings in schizophrenia plus epilepsy cases included 1 deletion 16 p13 and 1 duplication $7 q 11.23$ for a total of $12 / 235$
(5.1\%) while a possibly pathogenic duplication of $22 \mathrm{q} 11.2$ was found in one control for a total of 1 in $191(0.5 \%)$ controls (Fisher's exact test, $\mathrm{p}=0.008)$. We also wished to assess whether our data supported the hypothesis that disease-associated CNVs would be more common in cases of schizophrenia and epilepsy compared to unselected schizophrenia. The rate of abnormality in the schizophrenia plus epilepsy of 10 / 235 for the more definite CNVs compares to a rate of $75 / 7336$ based on supplemental data from Levinson et al. [19] for these same CNVs in a series of unselected schizophrenia cases (Fisher's exact test, $\mathrm{p}=0.0004$ ).

There are weaknesses in the current study including the use of cell line DNA rather than blood derived DNA, self-reporting of epilepsy findings, less than optimal phenotypic information, lack of availability of parental DNA, and lack of complete matching of ethnicity of cases and controls. Despite these difficulties, the observed differences are so substantial that they indicate that the frequency of disease-associated CNVs is significantly higher than any control group and significantly higher than in any series of unselected schizophrenia cases. Based on these results, clinicians can reasonably expect a pathological $\mathrm{CNV}$ detection rate of about $5 \%$ if they study patients with both schizophrenia and idiopathic epilepsy. In addition, all of these samples are readily available to diagnostic laboratories for validation of testing. These data, along with progress in whole exome and whole genome sequencing, suggest that the time is approaching when molecular genetic analysis of schizophrenia patients will be a clinically useful activity.

\section{Conclusions}

The data presented here strongly suggest that diseaseassociated CNVs were present at a significantly higher frequency in cases with both schizophrenia and epilepsy compared to control samples from the same repository. In addition, disease-associated CNVs were found at a significantly higher frequency in schizophrenia plus epilepsy cases than in larger series of unselected schizophrenia. Although many geneticists would argue that chromosomal microarray analysis (CMA) is clinically useful today in patients with either schizophrenia or idiopathic epilepsy alone, the case for CMA testing is more compelling for individuals with both schizophrenia and epilepsy. The detection rate of clinically significant abnormalities is increasing with exon by exon coverage for hundreds of genes [22]. Although the frequency of pathological finding may be regarded by some as relatively low, definitive abnormalities can clarify diagnosis, inform genetic counseling, and potentially lead to CNVspecific management [53]. 
Table 4 CNVs in psychiatric screened controls

\begin{tabular}{|c|c|c|c|c|c|c|c|c|}
\hline NIMH ID & Sex & Chr. & Start & $\operatorname{size}(b p)$ & & Genes & Validation $^{a}$ & $D G V$ \\
\hline $150-10762$ & $\mathrm{~F}$ & $2 \mathrm{p} 21$ & 44549759 & 8313 & Loss & PREPL & Cus4 & None \\
\hline $150-11782$ & $\mathrm{~F}$ & $3 p 26.3$ & 2695544 & 355319 & Loss & CNTN4 & Cus3 & 6 overlap \\
\hline $150-10112$ & M & $3 q 29$ & 196860921 & 478408 & Gain & $D L G 1, B D H 1$ & Cat & 6 overlap \\
\hline $150-13123$ & M & $6 q 15$ & 89803425 & 144012 & Loss & SFRS13B, PM20D2, GABRR1 & Cus4 & None \\
\hline $150-12782$ & M & $5 p 13.2$ & 37534374 & 305290 & Gain & WDR70, GDNF & Cus3 & None \\
\hline $150-12491$ & M & $7 p 22.1$ & 5667980 & 255505 & Gain & RNF216, ZNF815, OCM & Cat & 2 overlap \\
\hline $150-11643$ & $\mathrm{~F}$ & $7 q 21.13$ & 88200226 & 354752 & Loss & ZNF804B, MGC26647 & Cus4 & 8 overlap \\
\hline $150-10750^{a}$ & $\mathrm{~F}$ & $8 p 21.3$ & 22211184 & 167245 & Gain & PIWIL2, SLC39A14, PPP3CC & Cus4 & 2 overlap \\
\hline $150-12293$ & M & $8 q 12.1$ & 56682642 & 214806 & Gain & TMEM68, TGS1, LYN, RPS20 & Cat & 4 overlap \\
\hline $150-12964$ & M & $9 q 21.32$ & 86522765 & 193620 & Gain & 5 genes & Cus4 & 3 overlap \\
\hline $150-10354$ & M & $9 q 31.1$ & 105642367 & 226151 & Loss & CYLC2 & Cus4 & 1 overlap \\
\hline $150-10750^{a}$ & $\mathrm{~F}$ & $9 q 34.3$ & 140374217 & 229402 & Gain & 9 genes & Cus4 & None \\
\hline $150-12487$ & M & $12 q 12$ & 40789970 & 3711960 & Gain & 13 genes & Cat & None \\
\hline $150-12111^{a}$ & M & $12 \mathrm{q} 24.12$ & 112181037 & 136012 & Gain & ACAD10, ALDH2, C12orf47, MAPKAPK5 & Cus4 & None \\
\hline $150-10678$ & $\mathrm{~F}$ & $12 \mathrm{q} 24.21$ & 116367980 & 170923 & Gain & MED13L & Cus4 & 1 overlap \\
\hline $150-10629$ & M & $13 q 33.1$ & 103192748 & 327792 & Gain & 7 genes & Cat & None \\
\hline $150-12138$ & M & $15 q 11.2$ & 22842143 & 244550 & Gain & TUBGCP5, CYFIP1, NIPA2, NIPA1 b & MLPA & Common \\
\hline 150-11886 & M & $15 q 11.2$ & 22842143 & 244550 & Gain & TUBGCP5, CYFIP1, NIPA2, NIPA1 b & Cat & Common \\
\hline $150-12900$ & M & $15 q 11.2$ & 22842143 & 244550 & Loss & TUBGCP5, CYFIP1, NIPA2, NIPA1 & MLPA & Common \\
\hline $150-11785$ & $\mathrm{~F}$ & $15 q 13.3$ & 31730445 & 694760 & Gain & CHRNAT ${ }^{\mathrm{C}}$ & Cat & Common \\
\hline $150-11943$ & M & $15 q 15.1$ & 42656727 & 32418 & Loss & CAPN3 & Cus4 & None \\
\hline $150-12111^{\mathrm{a}}$ & M & $16 p 13.3$ & 2147596 & 18151 & Gain & PKD1 & Cus4 & 3 overlap \\
\hline $150-12420$ & M & $17 p 13.2$ & 4027661 & 492396 & Gain & 10 genes $^{b}$ & Cat & 4 overlap \\
\hline $150-10080$ & M & $17 p 13.1$ & 9993838 & 416496 & Gain & 5 genes & Cat & None \\
\hline $150-12837$ & M & $17 p 11.2$ & 21195549 & 306380 & Gain & MAP2K3, KCNJ12, C17orf51 b & Cat & 13 overlap \\
\hline $150-12522$ & M & $19 q 13.11$ & 32809424 & 217110 & Loss & ZNF507, DPY19L3 & Cus4 & None \\
\hline $150-10660$ & $\mathrm{~F}$ & $21 q 22$ & 35720798 & 185606 & Gain & KCNE2, FAM165B, KCNE1, RCAN1 & Cus4 & Identical \\
\hline 150-10685 & M & $22 q 11.21$ & 18900180 & 2901481 & Gain & 50 genes & Cat & Common \\
\hline 150-10702 & M & Xp22.12 & 19563240 & 384858 & Gain & SH3KBP1, CXorf23 & Cat & None \\
\hline $150-12093$ & M & Yp11.2 & 9523339 & 126272 & Gain & 8 genes & Cus4 & None \\
\hline
\end{tabular}

Abbreviations: As in Table 1.

a denotes samples having more than one CNV

${ }^{b}$ denotes controls which had a similar call to CNV found in cases

\section{Additional material}

Additional file 1: Supplementary. Additional details regarding

methods, data analysis, and validation of findings as well as other results not discussed in the text can be found here.

\section{Acknowledgements and Funding}

The work was supported by grants from the US National Institutes of Health grants HD-037283 and HD-024064 (Intellectual and Developmental Disease Research Center) (both A.L.B.) and M01-RR00188 (General Clinical Research Center) (L.S.), and T32 GM-008307 (A.L.H.).

\section{Authors' contributions}

LRS and ALB designed the study. LRS and ALH performed experiments. SHLK assisted LRS and ALH in interpretation of data. CAS provided statistical analysis. LRS and ALH drafted the manuscript. ALB supervised all activities and was responsible for the final version of the manuscript.

\section{Competing interests}

All authors are based in the Department of Molecular and Human Genetics at Baylor College of Medicine (BCM), which offers extensive genetic laboratory testing, including use of arrays for genomic copy number analysis, and derives revenue from this activity.

Received: 4 May 2011 Accepted: 25 November 2011

Published: 25 November 2011

\section{References}

1. Shprintzen RJ, Goldberg R, Golding-Kushner KJ, Marion RW: Late-onset psychosis in the velo-cardio-facial syndrome. Am J Med Genet 1992, 42:141-142.

2. Bassett AS, Chow EW, Husted J, Weksberg R, Caluseriu O, Webb GD, et al: Clinical features of 78 adults with $22 q 11$ Deletion Syndrome. Am J Med Genet A 2005, 138:307-313.

3. Stefansson H, Rujescu D, Cichon S, Pietilainen OP, Ingason A, Steinberg S, et al: Large recurrent microdeletions associated with schizophrenia. Nature 2008, 455:232-236.

4. International Schizophrenia Consortium: Rare chromosomal deletions and duplications increase risk of schizophrenia. Nature 2008, 455:237-241. 
5. Niklasson L, Rasmussen P, Oskarsdottir S, Gillberg C: Autism, ADHD, mental retardation and behavior problems in 100 individuals with 22q11 deletion syndrome. Res Dev Disabil 2009, 30:763-773.

6. Mefford HC, Sharp AJ, Baker C, Itsara A, Jiang Z, Buysse K, et al: Recurrent Rearrangements of Chromosome 1q21.1 and Variable Pediatric Phenotypes. N Engl J Med 2008, 359:1685-1699.

7. Sebat J, Levy DL, McCarthy SE: Rare structural variants in schizophrenia: one disorder, multiple mutations; one mutation, multiple disorders. Trends in Genetics 2009, 25:528-535.

8. Helbig I, Mefford HC, Sharp AJ, Guipponi M, Fichera M, Franke A, et al: $15 q 13.3$ microdeletions increase risk of idiopathic generalized epilepsy. Nature Genet 2009, 41:160-162.

9. Shinawi M, Schaaf CP, Bhatt SS, Xia Z, Patel A, Cheung SW, et al: A small recurrent deletion within $15 q 13.3$ is associated with a range of neurodevelopmental phenotypes. Nat Genet 2009, 41:1269-1271.

10. Rodriguez-Santiago B, Brunet A, Sobrino B, Serra-Juhe C, Flores R, Armengol $L$, et al: Association of common copy number variants at the glutathione S-transferase genes and rare novel genomic changes with schizophrenia. Mol Psychiatry 2010, 15:1023-1033.

11. McCarthy SE, Makarov V, Kirov G, Addington AM, McClellan J, Yoon S, et al: Microduplications of $16 \mathrm{p} 11.2$ are associated with schizophrenia. Nature Genet 2009, 41:1223-1227.

12. Vassos E, Collier DA, Holden S, Patch C, Rujescu D, St CD, et al: Penetrance for copy number variants associated with schizophrenia. Hum Mol Genet 2010, 19:3477-3481.

13. Mulle JG, Dodd AF, McGrath JA, Wolyniec PS, Mitchell AA, Shetty AC, et al Microdeletions of 3q29 confer high risk for schizophrenia. Am J Hum Genet 2010, 87:229-236

14. Ingason A, Kirov G, Giegling I, Hansen $T$, Isles AR, Jakobsen $\mathrm{KD}$, et al: Maternally derived microduplications at 15q11-q13: implication of imprinted genes in psychotic illness. Am J Psychiatry 2011, 168:408-417.

15. Kumar RA, KaraMohamed S, Sudi J, Conrad DF, Brune C, Badner JA, et al: Recurrent 16p11.2 microdeletions in autism. Hum Mol Genet 2008, 17:628-638.

16. Weiss LA, Shen Y, Korn JM, Arking DE, Miller DT, Fossdal R, et al: Association between microdeletion and microduplication at 16p11.2 and autism. N Engl J Med 2008, 358:667-675.

17. Makikyro T, Karvonen JT, Hakko H, Nieminen P, Joukamaa M, Isohanni M, et al: Comorbidity of hospital-treated psychiatric and physical disorders with special reference to schizophrenia: a 28 year follow-up of the 1966 northern Finland general population birth cohort. Public Health 1998, 112:221-228

18. Sanders AR, Levinson DF, Duan J, Dennis JM, Li R, Kendler KS, et al: The Internet-based MGS2 control sample: self report of mental illness. Am J Psychiatry 2010, 167:854-865.

19. Levinson DF, Duan J, Oh S, Wang K, Sanders AR, Shi J, et al: Copy number variants in schizophrenia: confirmation of five previous findings and new evidence for $3 q 29$ microdeletions and VIPR2 duplications. Am J Psychiatry 2011, 168:302-316.

20. Redon R, Ishikawa S, Fitch KR, Feuk L, Perry GH, Andrews TD, et al: Global variation in copy number in the human genome. Nature 2006, 444:444-454.

21. Craddock N, Hurles ME, Cardin N, Pearson RD, Plagnol V, Robson S, et al Genome-wide association study of CNVs in 16, 000 cases of eight common diseases and 3, 000 shared controls. Nature 2010, 464:713-720.

22. Boone PM, Bacino CA, Shaw CA, Eng PA, Hixson PM, Pursley AN, et al: Detection of clinically relevant exonic copy-number changes by array CGH. Hum Mutat 2010, 31:1326-1342.

23. Ou Z, Kang SH, Shaw CA, Carmack CE, White LD, Patel A, et al: Bacterial artificial chromosome-emulation oligonucleotide arrays for targeted clinical array-comparative genomic hybridization analyses. Genet Med 2008, 10:278-289.

24. Shaw CJ, Shaw CA, Yu W, Stankiewicz P, White LD, Beaudet AL, et al: Comparative genomic hybridisation using a proximal 17p BAC/PAC array detects rearrangements responsible for four genomic disorders. J Med Genet 2004, 41:113-119.

25. Cheung SW, Shaw CA, Yu W, Li J, Ou Z, Patel A, et al: Development and validation of a CGH microarray for clinical cytogenetic diagnosis. Genet Med 2005, 7:422-432
26. Lu X, Shaw CA, Patel A, Li J, Cooper ML, Wells WR, et al: Clinical implementation of chromosomal microarray analysis: summary of 2513 postnatal cases. PLOS ONE 2007, 2:e327.

27. Ingason A, Rujescu D, Cichon S, Sigurdsson E, Sigmundsson T, Pietilainen OP, et al: Copy number variations of chromosome 16p13.1 region associated with schizophrenia. Mol Psychiatry 2011, 16:17-25.

28. Van der Aa N, Rooms L, Vandeweyer G, van den Ende J, Reyniers E, Fichera $M$, et al: Fourteen new cases contribute to the characterization of the 7q11.23 microduplication syndrome. European Journal of Medical Genetics 2009, 52:94-100.

29. Teltsh O, Kanyas K, Karni O, Levi A, Korner M, Ben-Asher E, et al: Genomewide linkage scan, fine mapping, and haplotype analysis in a large, inbred, Arab Israeli pedigree suggest a schizophrenia susceptibility locus on chromosome 20p13. Am J Med Genet B Neuropsychiatr Genet 2008, 147B:209-215.

30. Fanous AH, Neale MC, Webb BT, Straub RE, O'Neill FA, Walsh D, et al: Novel linkage to chromosome 20p using latent classes of psychotic illness in 270 Irish high-density families. Biol Psychiatry 2008, 64:121-127.

31. Thorgeirsson TE, Gudbjartsson DF, Surakka I, Vink JM, Amin N, Geller F, et al: Sequence variants at CHRNB3-CHRNA6 and CYP2A6 affect smoking behavior. Nat Genet 2010, 42:448-453.

32. Durner M, Zhou G, Fu D, Abreu P, Shinnar S, Resor SR, et al: Evidence for linkage of adolescent-onset idiopathic generalized epilepsies to chromosome 8-and genetic heterogeneity. Am J Hum Genet 1999, 64:1411-1419.

33. Ohnuma T, Kato H, Arai H, Faull RL, McKenna PJ, Emson PC: Gene expression of PSD95 in prefrontal cortex and hippocampus in schizophrenia. NeuroReport 2000, 11:3133-3137.

34. Kristiansen LV, Beneyto M, Haroutunian V, Meador-Woodruff JH: Changes in NMDA receptor subunits and interacting PSD proteins in dorsolateral prefrontal and anterior cingulate cortex indicate abnormal regional expression in schizophrenia. Mol Psychiatry 2006, 11:737-47, 705.

35. Liu FY, Wang XF, Li MW, Li JM, Xi ZQ, Luan GM, et al: Upregulated expression of postsynaptic density-93 and $\mathrm{N}$-methyl-D-aspartate receptors subunits $2 B$ mRNA in temporal lobe tissue of epilepsy. Biochem Biophys Res Commun 2007, 358:825-830.

36. Hammond JC, McCullumsmith RE, Funk AJ, Haroutunian V, MeadorWoodruff JH: Evidence for abnormal forward trafficking of AMPA receptors in frontal cortex of elderly patients with schizophrenia. Neuropsychopharmacology 2010, 35:2110-2119.

37. Sodhi MS, Simmons M, McCullumsmith R, Haroutunian V, MeadorWoodruff $J \mathrm{H}$ : Glutamatergic Gene Expression Is Specifically Reduced in Thalamocortical Projecting Relay Neurons in Schizophrenia. Biol Psychiatry 2011.

38. Mejias R, Adamczyk A, Anggono V, Niranjan T, Thomas GM, Sharma K, et al: Gain-of-function glutamate receptor interacting protein 1 variants alter GluA2 recycling and surface distribution in patients with autism. Proc Natl Acad Sci USA 2011, 108:4920-4925.

39. Walitza S, Wendland JR, Gruenblatt E, Warnke A, Sontag TA, Tucha O, et al Genetics of early-onset obsessive-compulsive disorder. Eur Child Adolesc Psychiatry 2010, 19:227-235.

40. Samuels J, Wang Y, Riddle MA, Greenberg BD, Fyer AJ, McCracken JT, et al: Comprehensive family-based association study of the glutamate transporter gene SLC1A1 in obsessive-compulsive disorder. Am J Med Genet B Neuropsychiatr Genet 2011, 156B:472-477.

41. Kantojarvi K, Onkamo P, Vanhala R, Alen R, Hedman M, Sajantila A, et al: Analysis of $9 \mathrm{p} 24$ and $11 \mathrm{p} 12-13$ regions in autism spectrum disorders: rs1340513 in the JMJD2C gene is associated with ASDs in Finnish sample. Psychiatr Genet 2010, 20:102-108.

42. Baca-Garcia E, Vaquero-Lorenzo C, Perez-Rodriguez MM, Gratacos M, Bayes M, Santiago-Mozos R, et al: Nucleotide variation in central nervous system genes among male suicide attempters. Am J Med Genet $B$ Neuropsychiatr Genet 2010, 153B:208-213.

43. Oades RD, Lasky-Su J, Christiansen H, Faraone SV, Sonuga-Barke EJ, Banaschewski T, et al: The influence of serotonin- and other genes on impulsive behavioral aggression and cognitive impulsivity in children with attention-deficit/hyperactivity disorder (ADHD): Findings from a family-based association test (FBAT) analysis. Behav Brain Funct 2008, 4:48-62. 
44. Arion D, Sabatini M, Unger T, Pastor J, Alonso-Nanclares L, BallesterosYanez I, et al: Correlation of transcriptome profile with electrical activity in temporal lobe epilepsy. Neurobiol Dis 2006, 22:374-387.

45. Barnby G, Abbott A, Sykes N, Morris A, Weeks DE, Mott R, et al: Candidategene screening and association analysis at the autism-susceptibility locus on chromosome 16p: evidence of association at GRIN2A and ABAT. Am J Hum Genet 2005, 76:950-966.

46. Kilpinen H, Ylisaukko-Oja T, Rehnstrom K, Gaal E, Turunen JA, Kempas E, et al: Linkage and linkage disequilibrium scan for autism loci in an extended pedigree from Finland. Hum Mol Genet 2009, 18:2912-2921.

47. Szafranski P, Schaaf CP, Person RE, Gibson IB, Xia Z, Mahadevan S, et al: Structures and molecular mechanisms for common $15 q 13.3$ microduplications involving CHRNA7: benign or pathological? Hum Mutat 2010, 31:840-850.

48. Vijayan NN, Iwayama Y, Koshy LV, Natarajan C, Nair C, Allencherry PM, et al: Evidence of association of serotonin transporter gene polymorphisms with schizophrenia in a South Indian population. J Hum Genet 2009, 54:538-542.

49. Grozeva D, Kirov G, Ivanov D, Jones IR, Jones L, Green EK, et al: Rare copy number variants: a point of rarity in genetic risk for bipolar disorder and schizophrenia. Arch Gen Psychiatry 2010, 67:318-327.

50. Lo-Castro A, Galasso C, Cerminara C, El-Malhany N, Benedetti S, Nardone AM, et al: Association of syndromic mental retardation and autism with 22q11.2 duplication. Neuropediatrics 2009, 40:137-140.

51. Firth HV: 22q11.2 Duplication. GeneReviews [http://www.ncbi.nlm.nih.gov/ sites/GeneTests/review?db=GeneTests].

52. Kirov G, Grozeva D, Norton N, Ivanov D, Mantripragada KK, Holmans P, et al: Support for the involvement of large CNVs in the pathogenesis of schizophrenia. Hum Mol Genet 2009, 18:1497-1503.

53. Cubells JF, Deoreo EH, Harvey PD, Garlow SJ, Garber K, Adam MP, et al: Pharmaco-genetically guided treatment of recurrent rage outbursts in an adult male with 15q13.3 deletion syndrome. Am J Med Genet A 2011, 155A:805-810.

\section{Pre-publication history}

The pre-publication history for this paper can be accessed here: http://www.biomedcentral.com/1471-2350/12/154/prepub

doi:10.1186/1471-2350-12-154

Cite this article as: Stewart et al:: High frequency of known copy number abnormalities and maternal duplication $15 q 11-q 13$ in patients with combined schizophrenia and epilepsy. BMC Medical Genetics 2011 12:154.

\section{Submit your next manuscript to BioMed Central and take full advantage of:}

- Convenient online submission

- Thorough peer review

- No space constraints or color figure charges

- Immediate publication on acceptance

- Inclusion in PubMed, CAS, Scopus and Google Scholar

- Research which is freely available for redistribution 